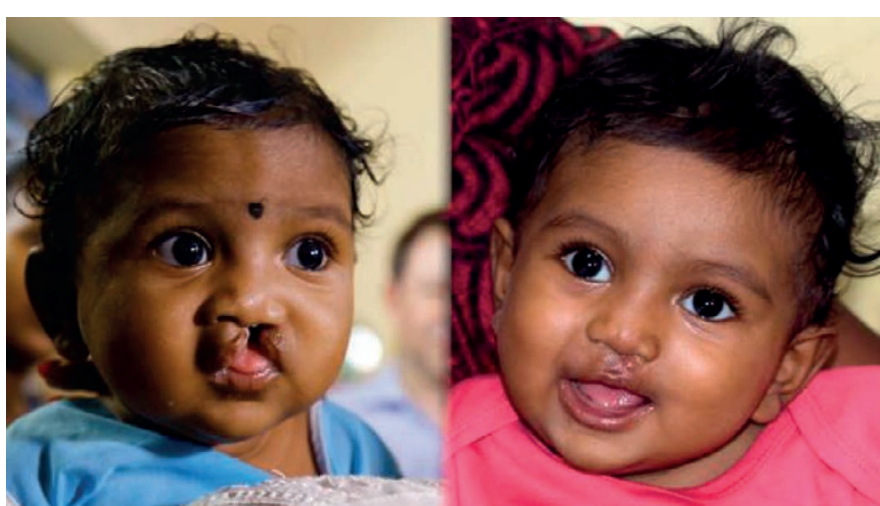

GSK Consumer Healthcare, a leading provider in specialist oral health, has announced a new five-year partnership with Smile Train, an international children's charity that empowers local medical professionals with training, funding, and resources to provide free cleft surgery and comprehensive cleft care to children globally.

Every year, one in 700 children are born with a cleft lip or palate globally. Clefts are the leading birth defect in many developing countries, and it is estimated more than 200,000 children are born with a cleft every year.

The announcement of this partnership comes at a pivotal moment for a baby girl in Chennai, India, Jaya, who is the recipient of the first GSK-funded cleft surgery.

Jaya was born in December 2017 with a complete unilateral cleft lip and palate, making it difficult for her mother to feed her.

Jaya was four months old when she underwent her first, successful cleft surgery performed by Smile Train's local partner, Dr Jyotsna Murthy at Sri Ramachandra Hospital, in April 2018. Jaya is doing well, but faces further surgery to fully correct her cleft palate. Her next surgery is scheduled for when she is nine months old.

Announcing the partnership, Brian McNamara, CEO GSK Consumer Healthcare, said: 'With GSK Consumer Healthcare's heritage in specialist oral health, we know the importance of a healthy mouth.
'Our five-year global partnership with Smile Train will help provide thousands more surgeries for children with clefts and help increase medical training in local communities. I'm delighted that our partnership is already having an impact and we're inspired by the difference weve been able to make to Jaya and her family. However, this partnership will go far further than our financial support alone.

'We're excited by the prospect of bringing together GSK's expertise and strength in oral health with Smile Train's knowledge and reputation in local communities to help increase awareness about cleft among both consumers and experts, and to provide vital support in oral health and hygiene for patients as part of the overall care pathway.

'We'll also be encouraging our employees to give their time, skills, and donations to support Smile Train.'

Susannah Schaefer, Executive Vice Chair and CEO of Smile Train said: 'These are exciting times for Smile Train and we're delighted to welcome GSK on board as a major corporate supporter of our work.

'Smile Train's unique, sustainable model provides training and funding to empower local medical professionals to provide $100 \%$-free cleft repair surgery and comprehensive cleft care at local medical facilities in the heart of their own communities. Our local medical partners are on the ground 365 days a year, continuously working to raise the level of care for all patients.

'Cleft repair surgery is safe, and the results are immediate. Coupled with comprehensive cleft care services, like speech therapy and orthodontics, children who have access to this care then have the opportunity to go on to lead healthy lives.

'Combining the expertise of GSK and Smile Train will strengthen our model, allow us to tap into a new network of experts, raise much needed awareness for children with clefts, and ultimately help us ensure more children like baby Jaya receive life-transforming cleft treatment.'

Over the next five years, GSK and Smile Train said they will work toward the goal of ensuring children born with clefts can lead full and productive lives, achieving their own potential and contributing to their community.

More information on the partnership can be seen at https://www. gsk.com/en-gb/about-us/smile-train-partnership/.

\title{
New dental imaging centre for Colchester opens
}

CT Dent's seventh UK imaging centre has now opened in Colchester, Essex.

With the main centre in London, Colchester now adds to the company's list of major UK cities where there is a need for dental imaging.

CT Dent was created to provide dental professionals with the best quality dental imaging, using the latest state of the art technology and it launched its first imaging centre in the UK in 2007 in Devonshire Place, London.

The new branch has the latest KaVo OP 3D Pro CBCT scanner, which has dose reduction technology (DRT) and fields of view ranging from $5 \times 5 \mathrm{~cm}$ to $13 \times 15 \mathrm{~cm}$.

Established in 2007, CT Dent has grown into the UK's leading independent provider for dental imaging with more than 10,000

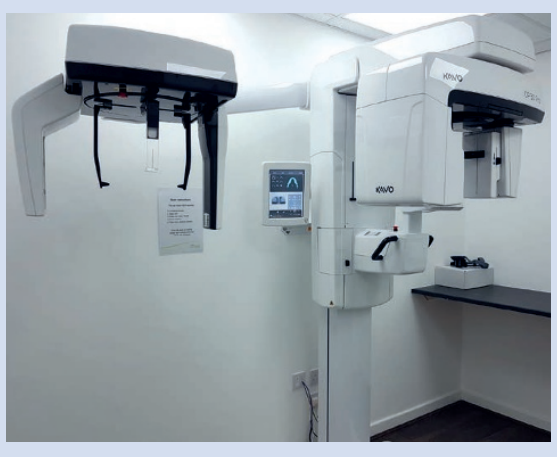

UK healthcare professionals using its services. CT Dent's seven imaging centres in the UK are in London, Manchester, Birmingham, Bristol, Nottingham, Leeds and Colchester.

Kfir Atias, Chief Executive Officer for CT Dent, says: 'We hope this new centre will help serve our dentist's patients, some of whom are travelling to London for scans. Our machines offer the latest dose reduction technology and our fast turnaround times mean we create a positive experience for our customers. We look forward to welcoming the patients to the centre, where all scans are taken by a fully qualified radiographer.

More information is available by visiting www.ct-dent.co.uk. 